\title{
Menos es más: Mies y la construcción paradójica de la arquitectura moderna
}

\author{
Less is more: Mies and the paradoxical construction \\ of modern architecture
}

\author{
FRANCISCO FELIPE MUÑOZ CARABIAS \\ Departamento de Composición Arquitectónica. Escuela de Arquitectura. Universidad de Alcalá \\ felipe.munoz@uah.es
}

Recibido: 10/06/2019

Aceptado: 20/10/2019

\section{Resumen}

En la creciente complejidad de la realidad, "less is more" (menos es más) representa, no tanto una reacción ascética ante la vida, como de un sentido de la misma desde la paradoja. Planta libre, muro cortina, tabique móvil, son ecos de estas relaciones aporéticas presentes en el proyecto moderno como producto de la disolución consciente de los límites marcados y sus diferencias. Sin embargo "less is more" encierra también una radicalidad solo posible desde la confrontación de estos dos términos opuestos. Este equilibrio de contrarios es lo que cristalizó en la obra de Mies van der Rohe, yendo más allá de su encasillamiento minimalista, que ocultó un planteamiento cercano a una construcción paradójica de la arquitectura moderna. Entender esta premisa ayudará a ampliar el enfoque de la supuesta coherencia que hubo en el proceso creativo de ese periodo clave de la historia de la arquitectura, inconcluso hasta el momento presente y abrirá la puerta a ampliar desde la hermenéutica, a un enfoque más plural de la producción arquitectónica contemporánea.

Palabras clave

Paradoja, Mies van der Rohe Arquitectura Moderna, proyecto, espacio, equivalencia. 


\begin{abstract}
In the growing complexity of reality, "less is more" represents, not so much an ascetic reaction to life, but a sense of it from the paradox. Free floor, curtain wall, mobile partition, are echoes of these aporetic relations present in the modern project as a product of the conscious dissolution of the marked boundaries and their differences. However "less is more" also contains a radicality only possible from the confrontation of these two opposite terms. This balance of opposites is what crystallized in the work of Mies van der Rohe, going beyond his minimalist typecasting, which concealed an approach close to a paradoxical construction of modern architecture. Understanding this premise will help to broaden the focus of the supposed coherence that existed in the creative process of that key period in the history of architecture, unfinished until the present moment and will open the door to expand from hermeneutics to a more pluralistic approach the contemporary architectural production.
\end{abstract}

\title{
Keywords
}

Paradox, Mies van der Rohe, Modern Architecture, project, space, equivalence.

Referencia normalizada: MUÑOZ CARABIAS, FRANCISCO FELIPE (2019): "Menos es más: Mies y la construcción paradójica de la arquitectura moderna". En Arte y Ciudad. Revista de Investigación, no 15-16 (2019), págs. 83-98. Madrid. Grupo de Investigación Arte, Arquitectura y Comunicación en la Ciudad Contemporánea, Universidad Complutense de Madrid.

Sumario: 1. =. 2. -. 3. +. 4. Menos = más. 5. Bibliografía.
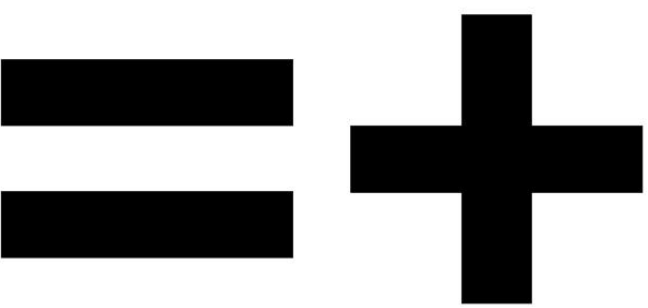

Fig. 1. -=+ Fuente: Imagen propia (2014). 
1. $=$

"Less is more" es sin duda uno de los aforismos más conocidos de la cultura moderna. "Ecuación poética" (Neumeyer, 2009), mantra invocado por muchos para expresar una posición existencial cercana a la austeridad autoimpuesta a la que obliga la conciencia dominante de lo sostenible. Como oxímoron ${ }^{1}$ es una contradicción aparente unida en una sola expresión que con el tiempo ha demostrado ser el resumen certero de una de las estéticas más genuinas de la modernidad a través de una figura como Mies van der Rohe. Su mentor más conocido pero no el autor de esta frase. De hecho solo se cree que la dijo en una conferencia de soslayo, como un axioma monástico atribuido por Philip Johnson al maestro alemán a modo de lema personal (Neumeyer, 2009: 20)².

Pero volviendo al principio, "less is more", que en el lenguaje matemático se expresa con la formula "- =+", es, sobre todo, y ante todo, una igualdad. "Less equals more" (menos es igual a más). Igualdad, que como principio de equivalencia en este caso nos aproxima a una paradoja, es decir, a una relación lingüística de integración de dos pensamientos opuestos que manifiestan un aparente sinsentido pero que sin embargo confluyen en una verdad plausible. Equivalencia que no supone una pérdida de las cualidades de los extremos sino más bien les da un sentido renovado. Producir sentido es la tarea de hoy, decía Deleuze, sabiendo que es el sinsentido lo que verdaderamente lo causa (Pla, 2005: 19-20). En La lógica del sentido, hablando de la paradoja en el lenguaje poético, ya señalaba su función potenciadora del inconsciente enviando sentido a la superficie desde las profundidades del mundo del sinsentido. Si los ideales de progreso basados en la razón fueron lo característico en los inicios de la modernidad, no fue menos el descubrimiento del subconsciente en su génesis. Toda la cultura de principios de siglo XX estuvo impregnada por el psicoanálisis, participando de este pensamiento paradójico que dio respuesta a una amplitud de lo real y de su naturaleza compleja. Así, aunque se optó por una ruptura con toda la tradi-

\footnotetext{
${ }^{1}$ Oxímoron (del griego ỏ $̧ u ́ \mu \omega \varrho o v$, oxymoron, en latín contradictio in terminis), figura lógica que consiste en usar dos conceptos de significado opuesto en una sola expresión.

2 Se sabe que formó parte de un poema dramático que Robert Browning escrito en el año 1855 con el título de "El pintor impecable"2 dedicado a Andrea del Sarto, un artista contemporáneo a Miguel Angel, que fue conocido por su extraordinario dominio de la técnica unido a un reproche generalizado hacia su obra por falta de alma. Toda una premonición.
} 
ción, fue solo con la más reciente donde se hizo más evidente esta escisión. Apoyándose en el mito del comienzo absoluto, la modernidad fue considerada "conciencia del presente como presente, sin pasado ni futuro y que en el fondo encerraba partes de la naturaleza de lo rechazado." 3 Su evolución, como indicaba Antoine Compagnon (2010, Introducción), se basó en la economía de una "tradición moderna", expresión esta absurda, en tanto en cuanto, implicaba equiparar tradición con ruptura. Personajes como Adolf Loos entendieron este dilema de "lo moderno" y, desde el uso de la paradoja, sus escritos actuaron de contrapeso al discurso oficial "coherente" que propugnaban las vanguardias. ${ }^{4}$ El propio Mies hablaba de "un arte de la vida portador del espíritu de la época". (Schulze, 2016: 45). Contradicción entre la antigua creencia en un orden existente a priori y la reivindicación contemporánea de una auto-legislación del propio sujeto, es lo que le movió, al igual que el hombre moderno según Nietzsche, a nadar entre dos aguas, y en el conflicto entre mitología e Ilustración, decir "simultáneamente sí y no" (Neumeyer, 2009: 155)5. Es decir, otra paradoja.

La propia condición de "proyectar" nos habla de "arrojar", prever el futuro con objetos del pasado. ${ }^{6}$ Lo moderno, por tanto, es hacer envejecer al presente, lo que llega para desplazarlo hacia atrás, hacia el pasado. De anticipar nuevas estructuras con antiguas piezas. La materia del proyectar son imágenes que movilizan la voluntad para modificar la realidad, pero estas viven en el mundo de la imaginación, del inconsciente, donde todo son fragmentos del pasado. El Movimiento Moderno fue revolucionario en su visión ${ }^{7}$

\footnotetext{
${ }^{3}$ La "eternidad" como habla Baudelaire en Las flores del mal.

4 "Pero incluso aquella manera de escribir aguada me ha acarreado la fama, no sólo por parte de los filisteos sino entre los artistas "modernos", por mi paradójica manera de escribir, de atacar por la espalda a lo "Moderno." (Loos, 2000: 25). Sorprendente si pensamos que los textos de arquitectura de aquella época solían utilizar un lenguaje sin fisuras, a veces, en clara contradicción con lo construido.

${ }^{5}$ Frente a la "mimesis de la apariencia", la "mimesis de la propia voluntad". Ya Giedion en Espacio, tiempo y arquitectura recoge una historia de lo moderno como una "construcción contradictoria" iniciando así una corriente dentro de la crítica de la arquitectura alejada de la línea oficial que tuvo su reflejo en Wittkower, Colin Rowe, o más recientemente, Robin Evans.

6 "Lo moderno es una máquina de anacronizar el presente" (Quetglas, 2001: 32).

${ }^{7}$ Gracias a las nuevas técnicas constructivas que permitieron ampliar el campo imaginario y los intercambios entre los movimientos artísticos.
} 
pero conservador en la materia con el que fue engendrado. ${ }^{8}$ Sin embargo, todo esto, lejos de ser estéril, supuso en este juego de paradojas, un capital de energía creativa inagotable. Decía Juan Navarro Baldeweg que el arte se caracteriza por su capacidad para hacer "fluctuar las ideas en direcciones opuestas" (Navarro, 1999: 77). Añadiría que sin renunciar a ninguna de ellas. Poner de manifiesto esta naturaleza inclusiva de lo paradójico es posiblemente clave para entender el cambio radical sin precedentes que se dio en el mundo del arte.

Las innumerables conexiones entre disciplinas que hubo, así como compartir una metodología análoga arte y la ciencia (Giedion, 430), tuvo como resultado una multiplicidad de relaciones entre distintas personalidades, Einstein/Picasso/Le Corbusier, Heisenberg/Schrödinger/Bohr/Mies y una fructífera contaminación mutua. ${ }^{9}$ Este último, permaneció unido durante toda su vida a una renovada visión de la naturaleza, la física y la filosofía, alcanzada en estos años (Neumeyer, 2009: 174) ${ }^{10}$. Una intuición acertada si tenemos en mente, como ejemplo, el cuadro Bodegón con flores de Juan Gris, donde se utiliza la técnica cubista de dividir los objetos y el espacio en fragmentos para, a continuación, juntarlos de nuevo sin diferencia alguna (Kahnweiler, 1997). Un paso lógico si se asume desde el arte el enigma de la ciencia de una materia divisible subatómica. El hecho de "mezclar" partes indistintas apela a un espacio y una materia que guardan entre ellos algún tipo de relación. Es aceptar en todo el proceso la paradoja de igualar diferentes.

\footnotetext{
${ }^{8}$ Luis Rojo lo indica claramente con el siguiente texto: “Lejos de hacerse realidad el deseo tantas veces manifestado por las vanguardias de hacer 'tabula rasa', prescindir de la Historia y comenzar desde cero, lo que realmente llegó a producirse fue una relación cubista de simultaneidad con el pasado".

${ }^{9}$ Mies tenía en su biblioteca La visión de la naturaleza de la física actual (1955), Física y Filosofía (1959) de Werner Hainsenberg; Física atómica y conocimiento humano de Niels Bohr; Ciencia y humanismo, la física de nuestro tiempo, de Schrödinger.

${ }^{10}$ Precisamente este último, Niels Bohr tenía colgado en la pared de su estudio, hacia los años treinta, un cuadro cubista de Metzinger, (Junto con Gleizes escribió un libro clave para entender estas transferencias de conocimiento entre estos dos mundos: sobre el cubismo) La mujer a caballo (Miller, 2007) porque necesitaba tener referentes plásticos para poder visualizar un universo cuántico.
} 


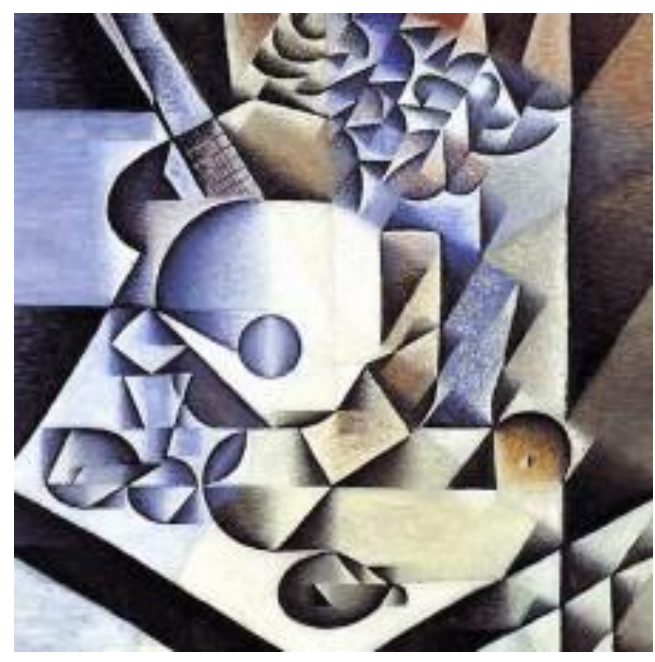

Figura 2. Naturaleza muerta con flores, Juan Gris (1912) Fuente: (C) 2016 The Museum of Modern Art. Nueva York.

Para la mayoría de nosotros hablar de "menos es más" se asocia directamente con el minimalismo. Sin embargo esto no fue así en sus orígenes. En el libro Less is More que Solá i Morales publica junto con otros autores, muchos de los trabajos expuestos denominados minimalistas, tienen su razón de ser a partir de la interacción dialéctica de dos formas aparentemente contradictorias: el propio minimalismo y el maximalismo (Solá, 2003). De hecho, este minimalismo o minimal $\operatorname{art}^{11}$ fue ya empleado en los años sesenta como contrapunto en su condición reductora para remarcar, de este modo, el carácter personalista del expresionismo abstracto (Foster, 2001). Lo que demuestra que el efecto requerido de "simplicidad" solo se consigue mediante una estrategia relacional con su opuesto y no en una estética depurada "per sé". Una obra de Pollock, como Ritmo de otoño, expresa, paradójicamente, de un modo intuitivo este acercamiento "desde lo opuesto" a una nueva concepción de la materia y del espacio. Desde lo inconsciente, lo arbitrario, el dripping, mecanismo de arrojar directamente pintura sobre un lienzo, se afirmaba como un proceso eficaz de plasmación de la homogeneidad desde la heterogeneidad absoluta, o el "all-over" consistente en no dejar ningún espacio sin cubrir, una especie de "horror vacui" que llenaba el lienzo, sobrepasando los límites del marco para sí dar a entender que era una parte de un conjunto infinito. Lleno frente a vacío. Espacio lleno como espacio matérico.

${ }^{11}$ El concepto Minimal Art fue acuñado por Richard Wollheim en 1965 y apareció, por primera vez, en un artículo suyo titulado de este modo que publicó en la revista Art Magazine. 


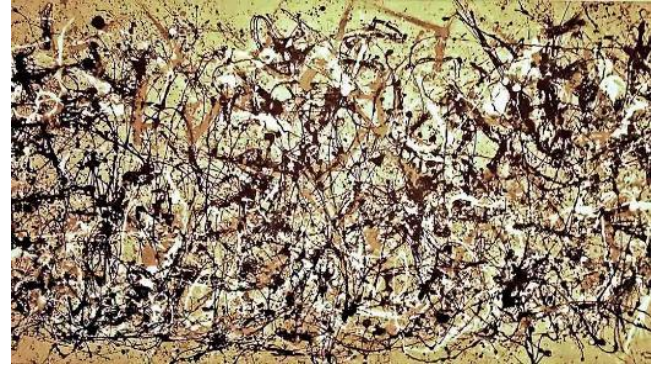

Fig. 3. Ritmo de Otoño Ritmo (Número 30) Autumn Rhythmn, Jackson Pollock (1950) (C) 2016 The Museum of Modern Art. Nueva York.

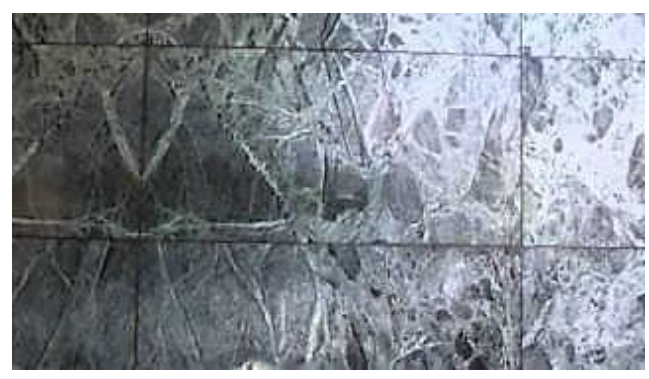

Fig. 4. Mármoles. Pabellón de Barcelona. Fuente: Imagen propia. Tomada con una PENTAX K7. (2014). Autorización Fundación Mies van der Rohe. Barcelona

\section{2. -}

En el minimal art la igualdad que subyace en el "less is more" está ligada a esa voluntad de conseguir un máximo orden con los mínimos elementos significativos (Guasch, 2000: 27), es decir, mediante configuraciones reducidas de orden y complejidad. El mayor interés por la totalidad de la obra supera las relaciones entre las partes singulares haciendo cumplir el principio gestáltico de que "todo es más que las partes". En una arquitectura como la de Mies van der Rohe, lo natural sería aproximarlo al minimalismo, sin embargo, como producto directo del material, es el detalle el generador del proyecto. Donde la parte es más que el todo. Si el minimalismo propone como origen la reacción contra las formas pictóricas del expresionismo abstracto a través de trabajos como los de Ad Reinhart, Malevich o Tatlin y en ciertos objetos no artísticos de contenido mínimo como los "ready mades" de Duchamp ${ }^{12}$; para Mies en cambio, sus intereses "reduccionistas" están más en la estética de la construcción e ingeniería de principios de siglo (Neumeyer, 2009: 230). Es verdad, que este componente material que delimita su campo de acción, se da por igual en artistas como Donald Judd o Dan Flavin (Solá-Morales, 2003: 37), pero incluso la negación absoluta por parte de estos artistas de "no significar nada", supone una intencionalidad añadida que paradójicamente en Mies no se da.

\footnotetext{
12 Su alusión no está demás si pensamos en su relación con el arte desde una cierta "indiferencia visual". Todo objeto está en igualdad de condiciones de llegar a ser obra de arte dado que esta es un constructo intelectual al margen de sus efectos visuales, o como él decía, desterrar "la excesiva importancia atribuida a la retina".
} 


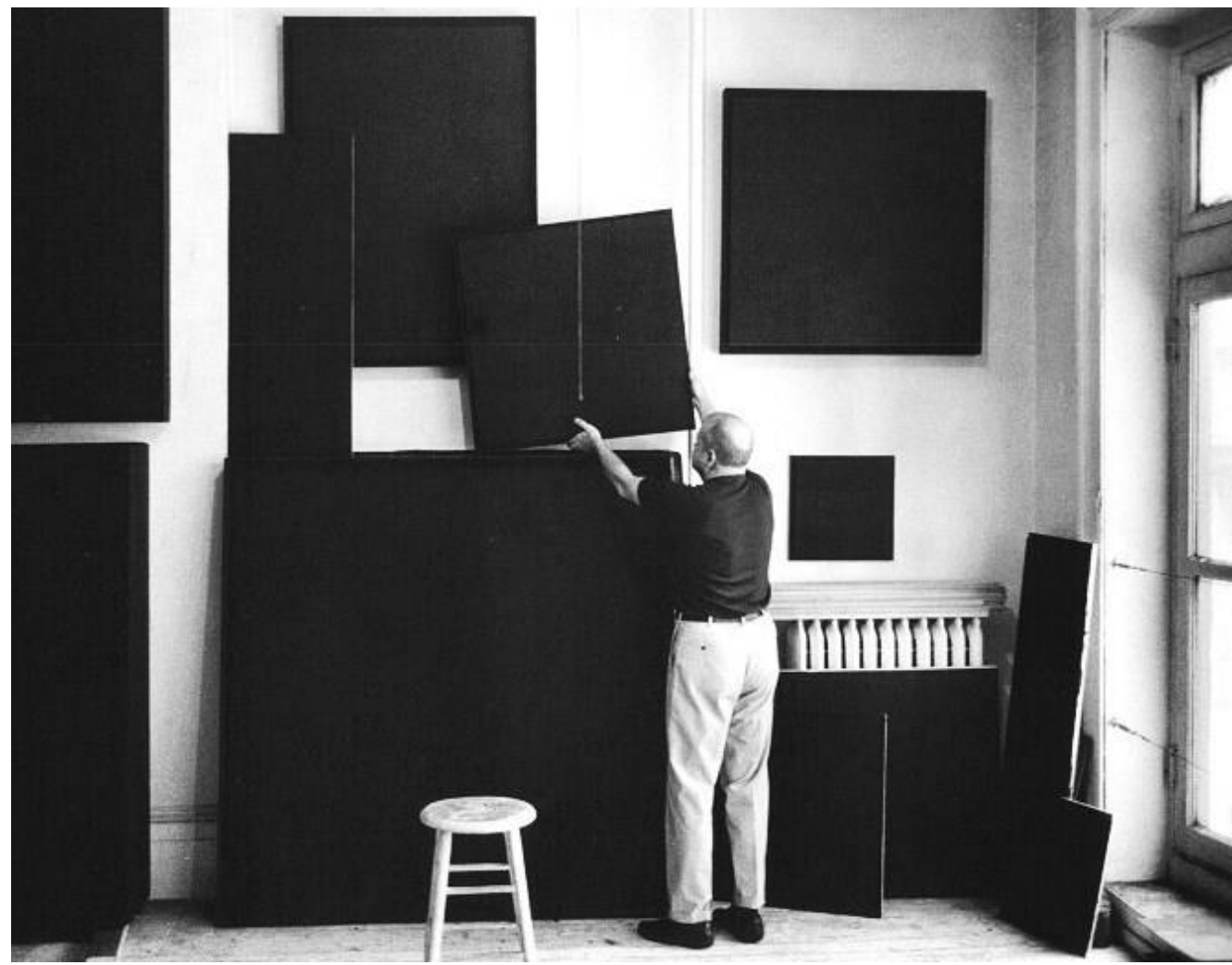

Figura 5. Ad Reinhardt Hangs Paintings Photo by John Loengard (1966)

(C) 1966 The LIFE Picture Collection/Getty Images

Me parece importante el caso de Reinhardt y sus llamadas pinturas "negras" de la década de los sesenta en esta afinidad-diferencia entre el minimalismo y Mies. Como culminación de su obra y de sus investigaciones, estos lienzos aparentemente monocromos, estaban en realidad compuestos por múltiples tonalidades del negro, en una continuidad de matices que le acercaban a una expresión de vacío "no solo como ausencia de materia" sino como cualidad de la naturaleza espacial dentro de esas modulaciones tonales. Impresiona ver la imagen de Reinhardt en su estudio y como se va "llenando" la habitación con lienzos de fragmentos de vacío en oposición a la propia realidad de los elementos comunes parcialmente ocultos como el radiador o la propia camisa del artista. No es solo negación del color y de la forma sino la afirmación "negativa" de una realidad paralela con su lógica opuesta que "no cuenta lo que se pone, sino 
lo que se deja de poner". Hay intuitivamente un acercamiento a ese otro mundo de la ausencia como contrapunto de la esfera de los objetos como obra de arte. Dos formas de responder. Una única realidad.

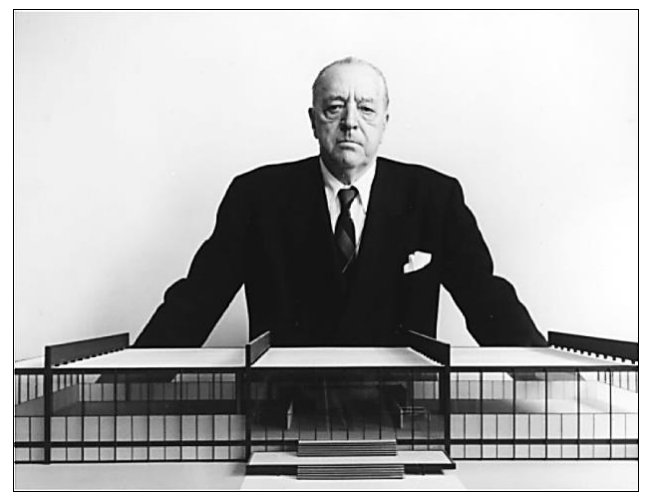

Fig. 6. Mies van der Rohe junto a la maqueta del S R Crown Hall (1950) (C) 1950 Chicago History Museum. Cortesia de Kruek and Sexton Architects.

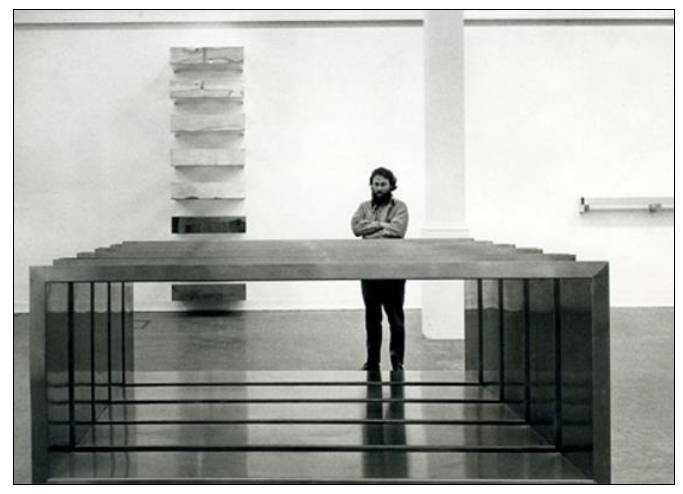

Fig. 7. Whitechape. Donald Judd (1970) Art ( Judd Foundation. Licensed by VAGA, New York, NY.

Ya anteriormente, el suprematismo había liberado a la pintura de toda la carga del objeto y de paso eliminado por completo todo indicio visual del mundo. Por lo tanto estaba en disposición de concentrar la atención solo en las cualidades del cuadro como única realidad. La ventana al mundo se había convertido en la apertura a otra realidad. Pero el cuadro se había reducido a la nada. Para Malevich esto significaba que "la mente inconsciente sería capaz de ver lo que el artista estaba presentando como cosmos al completo" (Gompertz, 2013). En todos los casos, el reduccionismo minimalista estuvo más cerca de una puesta en cuestión del propio objeto como significante que en cuestiones derivadas de la simplicidad de las formas. Donald Judd lo define con este pleonasmo de "objeto especifico", autista, autorreferencial; como lo es también la arquitectura de Mies al negar su condición significante. "Su arquitectura nunca es un monumento" proclama SoláMorales haciendo mención a la ausencia de significados externos a la propia obra miesiana. Algo parecido entonces, con los bloques de Judd fabricados en distintos materiales y de formas escultóricas simples "mudas" como "cajas", en secuencias de traslación de un mismo bloque repetido. Esta elección 
por lo cubico, por su condición neutra de la forma sin atributos, nos retrotrae a esa retícula cartesiana que es característica del "minimalismo" de Mies, donde el entramado portante de la estructura de pilares y vigas incorpora, "completa" una retícula geométrica de "orden rítmico fundamental en el espacio vacío" (Neumeyer, 2009: 153). Mies, por tanto, no está en el menos, o en el más, sino en la relación operativa de ambos.

No es casual que tengamos hoy, a cuarenta años de su muerte, continuos imitadores de su lenguaje minimalista, al cual no buscó sino que encontró en la paciente investigación de los recursos tecnológicos (técnicas y materiales) de su tiempo (Conenna, 2011).

Es el nexo que plantea Sola-Morales entre la experiencia estética del minimalismo y la obra miesiana, haciendo referencia al pensamiento deleuziano recogido en "Diferencia y repetición”. Otra vez la paradoja como construcción de sentido y salida a la falta de significación a partir del "desequilibrio en la idea monista ${ }^{13}$ de lo igual" (Solá-Morales, 2003) que introduce la repetición y la diferencia. La repetición como novedad, como mecanismo paradójico de libertad. En otras palabras,

la aparente simpleza expresiva es una trampa donde podemos caer si estamos sedientos sólo de minimalismo. Sin embargo, la auténtica verdad no está allí, pues ese es el resultado de una búsqueda más exhaustiva, relacionada con la explotación de los medios técnicos e industrializados que la época ofrece en cada momento. Imitar hoy su lenguaje es fomentar una ideología historicista postmoderna de la Modernidad más que reconocer lo esencial de su ideología arquitectónica (Conenna, 2011).

Es la vacuna contra "el aburrirnos enormemente" que comentaba el crítico de arte Meier-Grafe sobre los peligros de la técnica y el funcionalismo aplicados a la arquitectura. "Los opuestos son cualidades extremas que forman un potencial, las energías que proceden de los equilibrios dinámicos entre toda clase de opuestos" (Palazuelo, 1998).

\footnotetext{
${ }^{13}$ Postura filosófica que sostienen que el universo está constituido por un solo arjé, causa o sustancia primaria. Así, según los monismos materialistas, todo se reduce, en última instancia, a materia, mientras que para los espiritualistas o idealistas (especialmente el idealismo hegeliano), ese principio único sería el espíritu. Hay un Mies monista materialista y otro espiritual. Tal vez la paradoja esté en en esa dualidad vinculante.
} 


\section{3. +}

Volviendo a la expresión, podemos insistir en la condición de igualdad que encierra "less is more". En matemáticas, esta cualidad se establece mediante la comparación de valores representados a ambos lados del signo igual ${ }^{14}$. La forma de demostrarlo sería comprobar como cierto su contrario: más es menos. Una expresión provocadora pero probatoria. Si no hay muchas dudas sobre el "less is more", la constatación de un "more is less" en la arquitectura de Mies supone validar esta intuición en toda su profundidad. Centrándonos en su obra más significativa, el Pabellón de Barcelona, desmontemos uno de sus mitos: Su arquitectura no está desmaterializada sino más bien todo lo contrario. Ignasi Sola i Morales, en su texto Mies van der Rohe y el minimalismo, antes mencionado, ya indica que la "obra de Mies no parte de imágenes sino de materiales. Materiales en el sentido fuerte de la palabra" (Solá-Morales, 2003: 31-42). Otra cosa es que los materiales que utiliza, sobre todo en su etapa americana, sean el vidrio o el espacio, utilizado en igualdad de condiciones que los demás. Pero no siempre fue así. Incluso en los mismos muros de piedra del Pabellón. Bien es sabido que cuando tuvo oportunidad de usar el ladrillo lo hizo de una manera acorde con el propio material. El Monumento a Karl Liebknecht y Rosa Luxemburg es un ejemplo de ello. Mies trabajaba en la búsqueda de la esencia del material como base de la construcción, no en su "esencialidad" y eso es tanto como decir que su arquitectura se sustentaba en "realidades físicas desde el principio" (Solá-Morales, 2003: 36) y no en ausencias.

En Mies, "más es menos" como igualdad también se da. Lo que no es nunca una identidad: más es más o menos es menos. Esta idea es crucial para entender su arquitectura. La materia y el vacío son los que construyen, no buscando intermediarios conceptuales externos, ajenos a su propia naturaleza, sino basándose directamente en la relación paradójica que se da con ellos mismos, en la experiencia creada que los conforma y limita. Se dice que hubo una reducción de material pero el pilar del Pabellón de Barcelona pudo ser

\footnotetext{
${ }^{14}$ También de esta manera se demuestra una de las cinco propiedades que tiene la igualdad: la simétrica. Que consiste en poder cambiar el orden de los miembros sin que la igualdad se altere. Ejemplos: Si $39+11=50$, entonces $50=39+11$; Si a $-b=c$, entonces $c=a-b$; Si $x=y$, entonces $\mathrm{y}=\mathrm{x}$.
} 
más esbelto de lo que es. En un análisis estructural no exhaustivo se observa que los esfuerzos que soporta son muy diferentes de los utilizados por ejemplo en la casa Tugendhat. Y sin embargo los dos son del mismo tamaño. Al igual que los mármoles que se duplican por los reflejos. ¿Dónde está la austeridad? ¿Dónde la limitación y la contención? No hay un proceso de desmaterialización sino una (in)materialidad basada en la esencia y pureza de imágenes en constante equilibrio con la totalidad de los elementos que CONSTRUYEN su arquitectura. Materia y espacio (vacío) unidos en una abstracción. En una paradoja donde hay una materia que se espacia dentro de un espacio que se materializa. Le Ricolais lo fundamenta al definir una buena estructura: "si se piensa en los vacíos, en lugar de trabajar con los elementos sólidos, la verdad aparece" (Le Ricolais, 1973: 88)
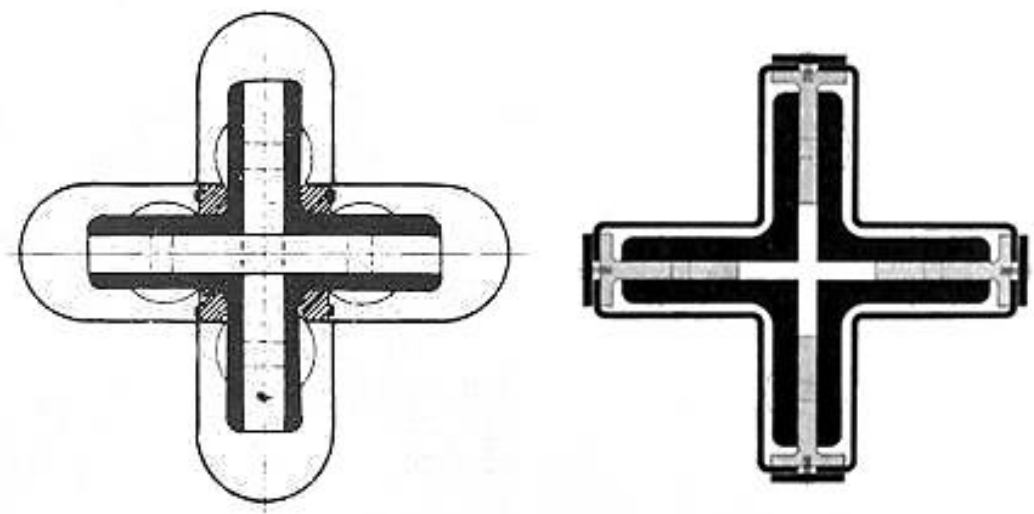

Fig. 8. Pilar del Pabellón de Barcelona + Pilar de casa Tugendhat. Autor: Mies van der Rohe. (C) 2016 Artists Rights Society (ARS), New York / VG Bild-Kunst, Bonn.

\section{4. menos = más}

En Mies, "menos es más" es la afirmación que nos lleva a una negación. Así la condición tectónica de su arquitectura es clara pero pasa por ser ingrávida. $\mathrm{Su}$ naturaleza es material pero su aspecto es desmaterializado. Toma muy en cuenta el lugar pero su condición autónoma es manifiesta. "Less is more" nos propone un modo de proyectar desde lo paradójico. Paradoja que se fundamenta filosóficamente en la teoría de opuestos extraída de las lecturas que 
Mies hizo principalmente de Guardini, ${ }^{15}$ y su juego de opuestos ${ }^{16}$. Una nueva "conciencia de unidad" en la Modernidad a través de estas fuerzas subjetivas limitadas por fronteras objetivas. Un equilibrio entre esta dualidad (Neumeyer, 2009: 305). Entre libertad y orden.

"Baukunst", palabra compuesta del alemán "Bau" (construcción) y “Kunst" (arte), es la paradoja sobre la que se construye el proyecto moderno como unión de dos conceptos contrapuestos entre sí. "En su Baukunst, como arte de la edificación, la retícula constructivo-estructural no es por tanto un concepto contrario al espacio, sino más bien una incorporación al mismo" (Ransoo, 2006). De hecho, la duplicidad de la estructura metálica hacia el exterior del edificio Seegram, por ejemplo, tiene esa finalidad "espacial" y no estructural. Mies decía que estos perfiles en doble $\mathrm{T}$ en bronce eran necesarios porque sin ellos el edificio "no quedaba bien" (Schulze, 2016: 251). Como el caso del Convention Hall donde las enormes cerchas podrían haber sido menores de haber colocado unos pilares interiores (Schulze, 2016: 260). Pero esto hubiese supuesto un "menos" en el "mas" conseguido por la estructura "espacial" de la cubierta. Menos gravedad con más estructura. También esa indiferencia ante cualquier situación, con independencia a su implantación, aunque haya una implicación total del interior con el entorno (Guirao, 2005). Es (in)gravido porque hay menos atracción entre los elementos. Es conformar una suspensión espacial, y temporal necesaria para que el edificio mantenga su sentido tectónico, entendiendo esto último como "construcción desde la gravedad". Su disposición está en función de ella, pero en última instancia, se inhibe. Es diseñar un pilar en su condición de pilar, una viga como viga, como elementos que obedecen a sus propias condiciones particulares. A una gravedad local. Los pilares del Seegram no varían su tamaño en toda su longitud. No atienden a las condiciones del conjunto resistentes sino a las propias derivadas del material. Las losas de la casa Fansworth flotan alterando el nudo de unión con el pilar.

\footnotetext{
${ }^{15}$ Neumeyer, 2009: 324. También de Simmel, Scheler y Bergson.

${ }^{16}$ Se ponía en relación al mismo Platón con el existencialismo. "Se remonta a Platón, (la Fisica de Aristoteles), al idealismo alemán y al pensamiento de opuestos de los siglos XIX y XX, y que había sido influida por Schopenhauer, Nietzsche, Kierkegaard, Bergson, Simmel, Scheler y Nicolai Hartmann" (Neumeyer, 2009: 302).
} 


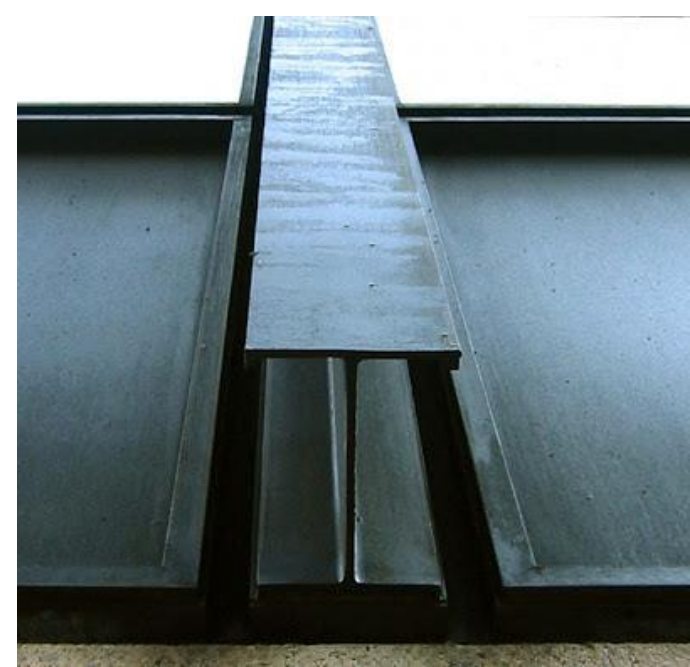

Fig. 9. Edificio Seagram. Detalle fachada. http://tectonicablog.com/?p=58754

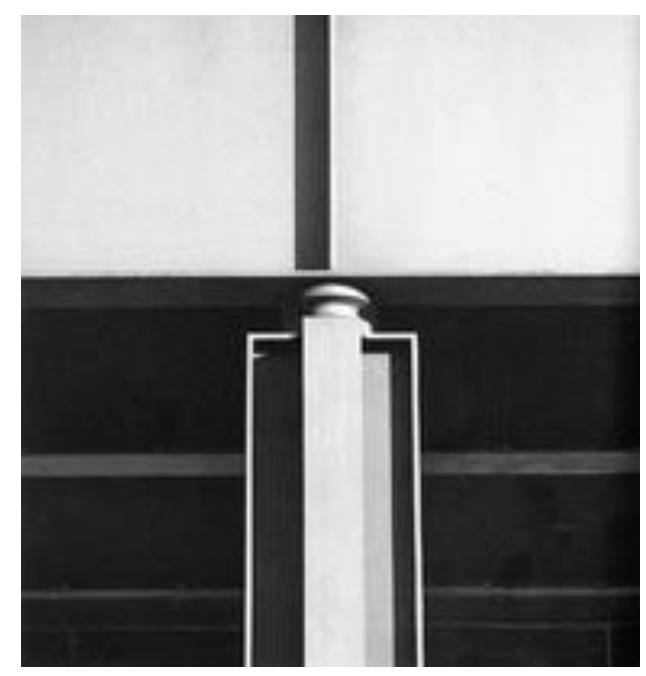

Fig. 10. Neue Nationalgalerie. Detalle. Vía Pinterest. Usuario Marco Jongmans

"Menos es más" no es una igualdad cualquiera. Es una paradoja "que construye arquitectura" desde esa equivalencia de opuestos. Solo en los límites de lo finito, de lo real, es posible esta afirmación. Solo desde el infinito, en el universo gobernado por el subconsciente, se igualan los pares. Solo desde el horizonte, siempre presente en la obra de Mies, el menos y el más, son disueltos en una unidad superior de materia vacía habitada. La cubierta de la Galería Nacional de Berlín, en su nudo de encuentro, es negada por medio de un "capitel ausente" rehundido en su propia sombra que termina por eliminarlo. ${ }^{17}$ Intuyendo este drama de inversos que se anulan. Cada uno independiente sin jerarquías. La retícula estructural llena de huecos disuelve el límite como piel. Al igual que el tiempo. Como otra variable en su continuidad con el espacio.

(In)acabado, apuntando a "suspender" la unidad para expresarse en ella misma. Para aspirar a más posibilidades en una estructura abierta llevada a menos. Una arquitectura potencial. Abierta.

${ }^{17}$ Quetglas (2001). El horror cristalizado. “En Berlín el capitel es una sombra" 


\section{Bibliografía.}

COMPAGNON, Antoine. Las cinco paradojas de la modernidad. México, D.F.: Siglo XXI Editores, 2010. ISBN 13: 9786070301384

CONENNA, Claudio (2011): “Lo Importante es lo Esencial. La filosofía proyectual de Mies van der Rohe (1886-1969)". Revista 47 al Fondo, no 20, junio, 2011, pp. 40-53.

GOMPERTZ, Will (2013). ¿Qué estás mirando? 150 años de arte moderno en un abrir y cerrar de ojos. Taurus, Madrid.

GUASCH, Anna María (2000). El arte último del siglo XX. Del postminimalismo a lo multicultural. Alianza, Madrid.

GASTON GuIRAO, Cristina. Mies: el proyecto como revelacion del lugar. Fundacion Caja de Arquitectos. 2005

HAL Foster (2001). El retorno de lo real. La vanguardia a finales de siglo. AKAL Madrid.

KAHNWEILER (1997): Juan Gris, Barcelona: Quaderns Crema.

LE RiCOLAIS. Interviews with Robert Le Ricolais, 1973 University of Pennsylvania, Filadelfia.

LOOS, Adolf (2000): Escritos I. Madrid: El Croquis.

MiLleR, Arthur (2007): Einstein y Picasso: el espacio, el tiempo y los estragos de la belleza. Tusquets, Barcelona.

NAVARRO BALDEWEG, Juan (1999): La Habitación vacante. Gerona: Pre-textos.

NEUMEYER, Fritz (2009): Mies van der Rohe: la palabra sin artificio. Reflexiones sobre arquitectura 1922-1968. Madrid: El Croquis.

Palazuelo, Pablo (1998): Escritos. Conversaciones. Colegio Oficial de Aparejadores y Arquitectos Técnicos de Murcia.

PLA, Maurici (2005). La arquitectura a través del lenguaje, Barcelona: Gustavo Gili.

Quetglas, Joseph (2001): El horror cristalizado. Imágenes del Pabellón de Alemania de Mies van der Rohe. Barcelona: Actar.

RANSOO, Kim (2006), The "Art of Building" (Baukunst) of Mies van Der Rohe. Dissertation, Georgia Institute of Technology, 2006

SCHUlZE, Franz (2016): Mies van der rohe. Una biografía crítica. Madrid: Reverte. 
SOlÁ-MORAlES, Ignasi (2003): Diferencias. Topografía de la arquitectura contemporánea Barcelona: Gustavo Gili.

VAN DeR ROHE, Ludwig Mies (1981): Escritos, Diálogos y Discursos. Murcia: Colegio Oficial de Aparejadores y Arquitectos Técnicos - Galeria-Libreria Yerba. 